the need for accurate estimates of prevalence of neurologic disorders. We would like to clarify a few points they raise regarding our estimate in relation to others.

First, our review was not a true meta-analysis; we did not pool the original data from the studies we reviewed because of their heterogeneity, instead we simply described the median and range of estimates the studies yielded.

While not ideal, the inherent limitations of extrapolating findings from other countries than the United States were reduced by restricting our review to studies in developed countries where advanced health care resources were generally available. The few recently published North American studies yielded some very high estimates of MS occurrence, perhaps related to the mainly northern European origin of the communities studied, a group associated with higher MS risk not representative of the entire US population.

Data reported directly from voluntary registries are not a reliable basis for estimating either incidence rates or prevalence in a population. Lack of motivation or knowledge among persons eligible to submit their names may lead to underreporting. Conversely, over-reporting may easily occur without adequate methods to adjust for duplicate reports, eliminate unverifiable or false reports, and account in a timely manner for deaths and out-migration. The possibility of major error-either overestimation or underestimation-is large.

Among all studies we reviewed, the median estimated prevalence of MS was 0.93 per 1,000. In comparison, the National Health Interview Survey of 1989 to 1994 yielded an MS prevalence estimate of $0.85 / 1,000$ population ${ }^{4}$ and a study of two counties in Colorado yielded 0.84/1,000. ${ }^{5}$ We did not include these two population-based studies in our review because Noonan et al. ${ }^{4}$ relied on selfreported diagnoses and Nelson et al. ${ }^{5}$ was published before 1990 .

Finally, our estimate was limited to definite or probable cases of MS. The earlier NIH estimate of MS prevalence of 1.2/1,0006 also included possible cases, which may account for much of the modest difference between the two estimates.

We strongly support relying on the best possible studies - and not anecdotal evidence or nonpopulation-based data-conducted in the same way over time, to inform us about the true frequency and time trends of diseases with major burden to the US population.

Deborah G. Hirtz, David J. Thurman, Katrina

Gwinn-Hardy, Robert Zalutsky, Rockville, MD
Disclosure: The authors report no conflicts of interest.

Copyright (C) 2007 by AAN Enterprises, Inc.

1. Hirtz D, Thurman DJ, Gwinn-Hardy K, Mohamed M, Chaudhuri AR, Zalutsky R. How common are the “common" neurologic disorders? Neurology 2007;68: 326-337.

2. Pugliatti M, Sotgiu S, Rosati G. The worldwide prevalence of multiple sclerosis. Clin Neurol Neurosurg 2002;104:182-191.

3. Orton SM, Herrera BM, Yee IM, et al. Sex ratio of multiple sclerosis in Canada: a longitudinal study. Lancet Neurol 2006;5:932-936.

4. Noonan CW, Kathman SJ, White MC. Prevalence estimates for MS in the United States and evidence for an increasing trend for women. Neurology 2002;58:136138.

5. Nelson LM, Hamman RF, Thompson DS, et al. Higher than expected prevalence of multiple sclerosis in northern Colorado. Neuroepidemiology 1986;5:17-28.

6. Anderson DW, Ellenberg JH, Leventhal CM, et al. Revised estimate of the prevalence of multiple sclerosis in the United States. Ann Neurol 1992;31:333-336.

\section{FREQUENCY OF AND RISK FACTORS FOR HIV DEMENTIA IN AN HIV CLINIC IN SUB-SAHARAN AFRICA}

To the Editor: Both Wong et al. ${ }^{1}$ and Brew and Gonzalez-Scarano ${ }^{2}$ make a strong case that HIVassociated dementia (HAD) merits more attention in sub-Saharan Africa, not only because it is treatable, but also because of HAD's possible adverse effects on HIV treatment compliance.

Treatment guidelines vary between countries in sub-Saharan Africa, but many recommend treatment initiation not only for patients with CD 4 counts under 200 cells $/ \mu$ L but also with WHO stage IV clinical disease (which includes HAD). ${ }^{3}$ The overall CD4 counts quoted include patients taking treatment and might overestimate the prevalence of HAD in patients presenting with CD4 counts over 200.

It would be helpful if the authors could describe how many of their patients would have qualified for treatment on CD4 criteria and how many would require a clinical diagnosis to start treatment. Regardless of whether a diagnosis of HAD is required to start treatment, monitor progress, or predict treatment outcome, the challenges of diagnosing HAD in resourceconstrained settings are substantial. Wong et al. ${ }^{1}$ used a battery of neuropsychological tests and a neurological assessment to diagnose HAD. Most health care systems in sub-Saharan Africa have few clinical staff and are unlikely to be able to conduct the tests used in this study. Simple tools, drawn from the extensive battery of tests described and requiring minimal expertise to de- 
liver, are therefore vital to screen for HAD. It would be interesting if the authors could identify which tests might be useful to be developed for a routine clinical setting.

While we agree with Brew and GonzalezScarano $^{2}$ that there is a possibility that cognitive impairment might lead to poor treatment compliance and subsequent possible increased transmission of resistant virus, the statement that "cognitively impaired patients are less inhibited and are more likely to engage in HIV-related risk behavior" is not merited. The association between reduced inhibition and increased risky sexual behaviour has been studied mostly among gay and bisexual men in developed countries. ${ }^{4}$ The extent to which behaviors in these select populations can be extrapolated to general African populations is unclear. However, we support the authors in highlighting this as an important area for further study.

Nuala M. McGrath, Graham S. Cooke, Mtubatuba, South Africa

Disclosure: The authors report no conflicts of interest.

Reply from the Authors: We thank Drs. McGrath and Cooke for their interest in our article. Concerning the possible overestimation of the prevalence of HAD in individuals presenting with CD4 counts over 200, it should be noted that of the 24 patients who were diagnosed with HAD in our study, 20 had not received any antiretroviral (ARV) therapy in the past.

Of these 20 individuals, CD4 counts were available for 16 , and 6 of $16(37.5 \%)$ had CD4 counts greater than 200. In the group of 4 patients with HAD who were receiving or had received ARV therapy, only 1 of $4(25 \%)$ had a CD 4 count greater than 200. While the numbers are small, it still appears that a significant number of individuals who present with HAD have CD4 counts in excess of 200, and would require a clinical diagnosis to be started on ARV therapy.

Regarding the difficulty of making the diagnosis of HAD in a resource-limited setting, our group has done preliminary work validating a screening tool named the International HIV Dementia Scale for this purpose. The IHDS is a simple, three-part test that includes a four-word recall, finger tapping, and then alternating hand sequence test. It is scored out of 12 , and at a cutoff score of 10 , the test has a sensitivity of $80 \%$ and a specificity of $55 \% .^{5}$

The IHDS is the first step towards a simple means of making the diagnosis of HAD in health care systems where the resources are not available to perform extensive neurologic and neuropsychological testing. Within our neuropsychological test battery, tests of verbal memory (WHOUCLA Verbal Learning test trial 5 and delayed recall) and executive function (Color Trails Parts 1 and 2) were the tests most likely to demonstrate impairment.

Further studies should be performed to validate a brief, practical neuropsychological test battery for routine clinical screening of HAD in sub-Saharan Africa.

Matthew H. Wong, Charlottesville, VA;

Ned Sacktor, Baltimore, MD

Disclosure: The authors report no conflicts of interest

Reply from the Editorialists: We thank McGrath and Cooke for their comments regarding our editorial in Neurology. ${ }^{2}$ We share their concerns regarding the difficulties of delivering neurologic and psychiatric care in resource-limited areas, and we agree that there is a need for simpler tests that define impairment in such circumstances. In this regard, there are simpler cognitive tests ${ }^{6}$ and there are simpler motor-based tests. ${ }^{7}$ Nonetheless, there are still problems relating to normative data and availability of testing instruments.

Their comments raise an additional critical issue. There is a perception that a diagnosis of impairment cannot be made without neuropsychological evaluation. This is incorrect. Significant cognitive impairment in the form of dementia is a clinical diagnosis. Its accuracy is assisted by neuropsychological assessment but its validity is not dependent on neuropsychological evaluation. Awareness of the clinical features of the disorder (with corroboration from relatives and colleagues), followed by a careful neurologic examination and exclusionary tests, most importantly some form of brain imaging (where possible), are the cornerstones of diagnosis.

We also agree that the association between cognitive impairment and disinhibition has not been adequately studied, let alone proven, in African populations. Nonetheless, there are three mechanisms: through the association between cognitive impairment and psychiatric disease, most particularly hypomania, through the association between cognitive impairment and drug use, and most importantly through the association with apathy, a core feature of HIV-related dementia.

Apathetic patients do not take the initiative to ensure "safe" sex is practiced, especially in the "passive recipient" setting. It would be imprudent, in our view, not to take advantage of the 
lessons derived from research in developed countries while waiting for extensive further clinical studies that could take years to perform.

Bruce J. Brew, Sydney, Australia; Francisco

Gonzalez-Scarano, Philadelphia, PA

Disclosure: The author reports no conflicts of interest.

Copyright (C) 2007 by AAN Enterprises, Inc.

1. Wong MH, Robertson K, Nakasujja N, et al. Frequency of and risk factors for HIV dementia in an HIV clinic in sub-Saharan Africa. Neurology 2007;68:350-355.

2. Brew BJ, Gonzalez-Scarano F. HIV-associated dementia: an inconvenient truth. Neurology 2007;68:324-325.

3. WHO. WHO Case definitions of HIV for surveillance and revised clinical staging and immunological classifi- cation of HIV-related disease in adults and children. Geneva: WHO; 2006.

4. Semple SJ, Zians J, Grant I, Patterson TL. Sexual compulsivity in a sample of HIV-positive methamphetamine-using gay and bisexual men. AIDS Behav 2006;10:587-598.

5. Sacktor NC, Wong M, Nakasujja N, et al. The International HIV Dementia Scale: a new rapid screening test for HIV dementia. AIDS 2005;19:1367-1374.

6. Carey, et al. Initial validation of a screening test battery for the detection of HIV-associated cognitive impairment. Clin Neuropsychol 2004;18:234-248.

7. Parsons TD, Rogers S, Hall C, Robertson K. Motor based assessment of neurocognitive functioning in resource-limited international settings. J Clin Exp Neuropsychol 2007;29:59-66. 


\title{
Neurology
}

\author{
FREQUENCY OF AND RISK FACTORS FOR HIV DEMENTIA IN AN HIV CLINIC \\ IN SUB-SAHARAN AFRICA \\ Nuala M. McGrath and Graham S. Cooke \\ Neurology 2007;69;411-413 \\ DOI 10.1212/01.wnl.0000278073.28318.66
}

This information is current as of July 23, 2007

\section{Updated Information \& Services}

References

Citations

Permissions \& Licensing

Reprints including high resolution figures, can be found at: http://www.neurology.org/content/69/4/411.full.html

This article cites 6 articles, 2 of which you can access for free at: http://www.neurology.org/content/69/4/411.full.html\#\#ref-list-1

This article has been cited by 1 HighWire-hosted articles: http://www.neurology.org/content/69/4/411.full.html\#\#otherarticles

Information about reproducing this article in parts (figures,tables) or in its entirety can be found online at:

http://www.neurology.org/misc/about.xhtml\#permissions

Information about ordering reprints can be found online: http://www.neurology.org/misc/addir.xhtml\#reprintsus

Neurology ${ }^{\circledR}$ is the official journal of the American Academy of Neurology. Published continuously since 1951, it is now a weekly with 48 issues per year. Copyright. All rights reserved. Print ISSN: 0028-3878. Online ISSN: 1526-632X.

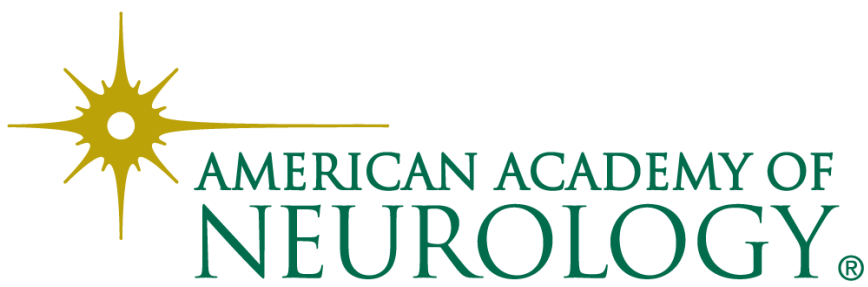

